\title{
Transmissions And Transformations: Comparing Danish Late-generation Ethnicity In America And Argentina
}

\author{
Pernille Skovgaard Christensen ${ }^{1}$ and Trine Lund Thomsen ${ }^{2}$ \\ Department of Culture and Learning, Aalborg University, Denmark
}

\begin{abstract}
This article explores the ethnic practices and self-perceptions of later generations of Danish immigrant descendants in the USA and Argentina. Through investigating their involvement in ethnic organisations and expressions of selfidentification, it engages in a concurrent debate on how ethnicity appears in those, perhaps, final stages. The comparison between later generation ethnics in the two countries shows remarkable differences, despite similar backgrounds and comparable generational stages. The study also shows, however, that possibilities for exploring ethnicity seem crucial to later self-identification. Ultimately, therefore, this seems to play a central role in defining the contours of the acculturation process through the generations.

Keywords: biographical narratives, Danishness, ethnic identity, ethnic practices, intergenerational transmission, late-generation ethnics.
\end{abstract}

\section{Introduction}

Between 1850 and 1924, massive waves of European migrants crossed the Atlantic in search of cheap land, wealth and freedom towards the West. Most of these, about 34 million, settled in America, including roughly 300.000 Danes - the equivalent of $10 \%$ of the Denmark's population at the time (Hvidt, 1976). Substantial numbers, however, chose other destinations, such as Argentina. Today, the descendants of the European migrants in the $4^{\text {th }}, 5^{\text {th }}$ and $6^{\text {th }}$ generation are what some scholars term 'late-generation ethnics' (LGE's).

Herbert Gans (2014) claims that LGE's in America are typically products of several ethnic intermarriages, and as they have multi-ethnic origins many have little memory, if any, of their immigrant ancestors. Thus, as their ethnicities may at this time be reduced to their symbols, Gans predicts that late-generation European ethnicity in America is coming to an end. However, Gans also stresses the absence of substantial research on ethnic identity in these later or perhaps final stages. He poses several interesting questions for further research. For example, he speculates upon whether newer waves of immigrants to America will eventually end up as LGE's themselves and 'repeat the extinction process'. Rightfully, the question should be asked whether there is a universality tied to acculturation processes, so that one can predict acculturation among migrants in other places and at different times to run through the same phases - to finally witness ethnicity's disappearance. What research has hitherto missed by overlooking the ethnicities of later generations is the study of an acculturation process stretching so far in time that it provides a unique chance to explore and understand acculturation across several generations, and on that account, to become able to learn from history.

Consequently, this article aims to contribute to a concurrent discussion of how ethnicity appears in its, perhaps, final stages. It does so by investigating LGE practices, i.e. how they 'do Danishness', and identifies their involvement in what Gans $(2014,2015)$ categorises as performing, preserving, commercial and promotional ethnic organisations. The article also investigates LGE identities, including the extent to which 'being Danish' continue to constitute individual self-perceptions or function as a component in hybrid or hyphenated identities. Finally, the article discusses how their maintenance of practices and self-perceptions may be explained.

In order to capture a more complex understanding of ethnicity's development and acculturation processes, the article makes use of a comparative research approach. Designed as a comparative case study, it compares the ethnic practices and identities of two groups of late-generation ethnics, more explicitly the descendants of the Danes who migrated in the latter half or the 19th and the beginning of the 20th centuries - to America and Argentina, respectively. Hence, this article presents some central findings from a rich qualitative life story material gathered on field trips to the USA and Argentina in 2013, 2014, 2015 and 2016.

From the mid 1800's and up to around 1930, about 13,000 Danes migrated to Argentina. Many settled in the rural area between the towns of Tandil, Tres Arroyos and Necochea, also called "Danskertrekanten" (the Danish triangle), where they mainly gained employment in agriculture, and in the province of Buenos Aires (Bækhøj, 1948; James, 2018; Kjær, 1991). In the triangle area there are currently approximately 50,000 citizens with Danish background. Compared to the roughly 300,000 Danes who migrated to the USA as part of the Great Migration from Europe in the latter part of the $19^{\text {th }}$ and the beginning of the $20^{\text {th }}$ centuries, the 13,000 who chose

\footnotetext{
1 skovgaard@hum.aau.dk

2 tlt@hum.aau.dk
} 
Argentina as their country of settlement is a relatively small number. As we return to, the patterns of settlement, however, look alike. According to the US 2010 census, there are just below 1,5 million people of Danish descent in the USA today. ${ }^{3}$

European migration to the Americas has been well researched, although to a greater extend to USA than to Argentina. Yet scholars on both sides of the Atlantic continue to discover new aspects and broaden the field further. In recent years particularly the historical placement of European ethnicities, including Scandinavian, within American ethno-racial hierarchies has been given attention (e.g. Blanck, 2014; Brøndal, 2014; Jacobson, 2006; Jackson, 2019), as has acculturation, (elastic) ethnic identities and yet more ethnic choices among LGE's (e.g. Gans, 2014, 2015; Jimenéz, 2010; Waters, 1990, 2014). In general, the discussion on ethnicity, ethnic identity and ethnic practices is continuously given attention (Jenkins, 2008, 2011; Phinney, 2003), especially as regards the relationship between ethnic exploration and engagement in ethnic practices on the one hand, and the commitment and personal self-identification on the other (e.g. Gans, 2014; Levitt \& Schiller, 2004; Phinney \& Ong, 2007; Tarman, 2012 - DELETE). As part of a discussion on the complex relationship between ethnic identity and acculturation (Berry, Phinney, Sam, \& Vedder, 2006; Phinney, 2003), scholars have more recently studied the background and implications of white privilege (Jackson, 2019; Lundström, 2014; Pease, 2010) and ethnic pride's effect on ethnic maintenance. Researchers have also debated whether later generation ethnicity is about to disappear (Gans, 2014, 2015; Kenna, \& Russell, 2018 - DELETE REF), whether one should instead speak of the emergence of a new European American ethnicity (Alba, 1990), or whether it even makes sense to keep talking about an ethnicity which is by now so profoundly influenced by American society (Alba, 1990; Øverland, 2000).

This article aims to contribute to the latter discussion especially, as mentioned above. Yet in this article, we avoid judging whether the ethnicities of the interviewees are more Danish, more Scandinavian or have become unalterably American/Argentinian. Instead, we concentrate on the life practices and identities which interviewees still term 'Danish' and explore, through intergenerational insights into LGE lives how and why they have largely maintained these and avoided complete assimilation this far. The study contrasts much contemporary research by proposing a more open way of understanding ethnic practices, identities and acculturative processes, based on individual life stories, family histories and dynamics of intergenerational transmission. This study includes glancing towards the impacts of religion as well as examining the importance of context, through which ethnicity can be explored and later internalised. In doing this, the article meets many of Gans' research suggestions. The data demonstrates that various factors may play a role in the continuous maintenance of ethnicity. While the comparison shows remarkable differences within the two cases, it simultaneously indicates that opportunity for engagement in ethnic spaces through the generations may play a significant role to later commitment and internalisation of ethnic identity as part of a matured identity and ultimately ethnic maintenance throughout several generations.

\section{Conceptual framework}

Acculturation in a new society concerns not only immigrants but also their descendants, being an intergenerational process. The classical definition of acculturation is that it "comprehends those phenomena which result when groups of individuals having different cultures come into continuous first-hand contact with subsequent changes in the original culture patterns of either or both groups" (Redfield, Linton, \& Herskovits, 1936, p. 149). Acculturation is a process of adaption using different strategies. Four types of strategies may be applied, and those are assimilation, separation, integration or marginalisation (Berry, 1997). Separation and pluralist integration are the only two strategies where there is a wish to maintain one's homeland culture.

Acculturation strategies may vary, depending on context and time period (length of residence or generational status) (Berry, 1989). Furthermore, there may be variation according to one's location, where cultural maintenance may be sought more in private spheres (such as the home, the extended family, the ethnic community) than in the public spheres (such as the workplace or in politics). There may also be less intergroup contact in private spheres than in the more public ones. The broader national context may also affect acculturation strategies. In explicitly multicultural societies, individuals may seek to match the policy with a personal preference for integration, whereas acculturation in more mono-cultural societies may be easiest by adopting an assimilation strategy (Krishnan \& Berry, 1992). In the USA and Argentina, being multicultural societies, the integration would be the preferred strategy for some immigrants and their descendants, which this study documents.

Some researchers have noted that different ethnic spaces are significant to ethnic persistence, because they have potentials to 'socialise a new generation to ethnic ways' (e.g. Alba, 1990, p. 254). According to Gans (2014), 'formal ethnic organisations and institutions are the most visible evidence of ethnicity's persistence'. Such organisations include what Gans categorises into four types: 1) promotional organisations which 'publicise and keep visible the ethnic population, its ethnicity, and the label by which the population is known'; 2) commercial organisations which are 'businesses that sell a variety of ethnic products and symbols such as foods, holiday

\footnotetext{
${ }^{3}$ US Census Bureau webpage, https://factfinder.census.gov/faces/tableservices/jsf/pages/productview.xhtml?pid=ACS_10_5YR_B04003\&prod Type=table, accessed on January $3^{\text {rd }} 2019$.
} 
paraphernalia and arts and crafts, some of them especially to tourists; 3) performing organisations which 'primarily hold festivals, many of them annual, with programmes of folk dances and ethnic music, theatre pieces and the like; and 4) preserving organisations which could be 'language classes, ethnic studies enterprises, community centers as well as university teaching and research centers and museums'. In this article we explore the degree to which LGE's take part in such ethnic spaces, in order to identify ethnic practices.

In Argentina and the USA, Danish ethnic identity has, like other ethnicities, been influenced by different 'outer', structures, such as internal developments within ethnic communities, pressures of assimilation as well as additional migration from home countries (Douma, 2014, p. 14). This article, however, looks primarily to ethnic influences from the 'inside', exploring acculturation from a micro-and individual perspective. The life stories, on which this article is based, namely expose a broad range of intergenerational transmissions between generations, making it possible to explore developments within ethnic practices and identities (Bertaux \& Thompson, 2009; Miller, 2000). The transmissions also include different forms of capital (Bourdieu, 1986), not least social bonding capital (Putnam, 2000). Since this article aims to uncover how and why LGE's have 'stayed Danish', it is particularly interested in factors which have assisted successful transmission of 'Danishness' throughout the generations.

\section{Methodological Reflexions}

This article presents some central findings from a rich empirical material gathered on field trips to the USA and Argentina in 2013, 2014, 2015 and 2016. Designed as a comparative case study, it compares the ethnic practices and identities of two groups of late-generation ethnics, namely the descendants of the Danes who migrated in the latter half or the 19th and the beginning of the 20th centuries - to America and Argentina, respectively.

The comparative case study has one key strength. Finding patterns within more cases namely strengthens theory-building which, through the testing and validation of even more cases, can potentially generate new theory (Glaser \& Strauss, 2012). Comparing LGE practices in America and Argentina is found to be relevant as the two cases have a number of elements in common, yet also hold important differences. For example, both migrant groups fled from the hardships and poverty of Danish peasant life, at the same point in time. Both groups migrated in search of wealth, freedom and opportunity towards the West, and in both cases many attempted to reach this through settling as farmers on prairie and pampas (Bjerg, 1996, Hvidt, 1976, Kjær, 1991). The 'emigrants', moreover, were primarily the same: Young men and families, many employed in agriculture or in craftsmanship, as farmhands or maids; poor and in desperate lack of rights, possibilities or hopes for the future. Though some migrants within both groups were quick to let go of their Danish background and assimilate, both groups concurrently established Danish communities and organisations, built Danish churches, schools, communicated in Danish and through Danish newspapers and called their towns by Danish names. In some of these places, descendants continue to practice what they term 'Danishness' until this day, though as ethnic identity and practices have been transmitted through generations, they have been transformed and reconstructed in the process. The contextual difference between Argentina and the USA also makes the comparison of the two country cases interesting and relevant for the study of acculturation over time and generations. One of the differences is the fact that the protestant Danes differed more profoundly from the dominant religion of Catholicism in Argentina. This made the establishing Danish Evangelical Lutheran churches with their own ministers more important in Argentina than in the USA. Another aspect which might have been significant to variations in ethnic maintenance in the two countries is the fact that despite their common goal of migrating to 'the Americas', Danes were more visibly different in the south than in the north.

The two cases include biographical narrative interviews with descendants of Danish immigrants. This type of interview provides an open-ended approach to retrieving knowledge about the individual, giving an explorative research approach (Rosenthal, 1993). The biographical narrative interview can contribute to the understanding of the reality that we all are a part of, although we can have different perception on the same reality (Bo, Christensen, \& Thomsen, 2016; Ricouer 1984). Together, these views provide a nuanced and multidimensional perspective of both subjectivity in lived life and the structures that frame the context in which social interaction takes place. An assumption in this study is therefore that LGE's perceived as individuals actively, but only to a certain extent, create their own identities in an intercultural context. Through the life stories, it becomes possible to identify the individual's sense of belonging and their ethnic identity.

\section{The Sample}

In the USA, 31 life story interviews were conducted with 'people of Danish descent' in the $2^{\text {nd }}-5^{\text {th }}$ generations, with an overweight of respondents in the $2^{\text {nd }}-4^{\text {th }}$ generations. The data collection took place in the late spring and early summer of 2014. Respondents were both solicited in two rural Danish settlements in the Midwest as well as in the urban environment of Chicago. In Argentina, 17 life story interviews were carried out with Danish descendants in the $2^{\text {nd }}-4^{\text {th }}$ generations upon a range of field trips from 2013-2016. The interviews were 
carried out in the Danish triangle as well as in Buenos Aires. Respondents in both country cases were distributed fairly evenly in terms of gender, with a slight overweight of females in the USA, and they all had a broad middleclass background. The age of respondents differed from young people in their late 20's to elderly people in their 80's. The interviews used in this article are primarily with $4^{\text {th }}$ generation ethnics and to a lesser extend $3^{\text {rd }}$ generation ethnics. We refer to them both as LGE's, but specify their generational stage as we proceed. The interviews used have an exemplary character as they represent experiences and views that are also expressed in other interviews.

In both country cases, respondents were asked to do the interviews in Danish or English, as they desired. In Argentina, only two interviews were carried out in English, while this was the case with almost all of those in the USA, except for one which, for the most part, was done in Danish. Since it quickly proved rather difficult to arrange interviews with families before arriving to the actual settlement, interviews often had to be planned dayto-day. This meant that the most fruitful recruitment strategies became the cooperation with certain gatekeeping individuals as well as effective snowballing.

As snowballing and gatekeepers were used as a primary means to obtain access to interviewees in both Argentina and the USA, it is important to note that the sample reflects a pool of descendants who moved within similar environments and who were often acquainted. It is also important to note that, since it was a specific request to speak with to 'people of Danish descent' in both Argentina and the USA, the total sample consists of people who, presumably more so than the average person of Danish descent, commit to their Danish ancestry. At least, the sample reflects a specific segment of people who to some extent know about and identify with their Danish background. Young LGE's were the hardest to get in contact with, since many felt they did not have much knowledge to share about their ancestors. Some young LGE's were recruited through their parents. As they were sometimes only sporadically affiliated with their ethnic heritage and did not necessarily move within the ethnic environments, they presumably represent a slightly more diverse segment of descendants.

Naturally, the recruitment of respondents places certain limitations to the outcome of this study. Consequent to the fact that the sample situates itself in a place where ethnic identity and practice has presumably survived the longest, the aim of this article is to explore how and why Danish Argentinian and Danish American LGE's have 'stayed Danish'.

\section{Exploring Ethnic Maintenance In LGE Life Stories}

Life stories are, as mentioned earlier, particularly suited for studying the self-perceptions of individuals and how these manifest in life practices. Vice versa, researchers claim, life practices also influence individual identities. Yet researchers suggest that ethnic practices and personal self-identification should be studied separately, since ethnic identities may exist without behavior (Phinney \& Ong, 2007). Consequently, the first part of the following analysis investigates how the LGE's in both Argentina and the USA 'do Danishness', through participating in ethnic organisations. The second part examines LGE expressions of Danish identities, making it possible to relate practices and identities and the circumstances which seem to have influenced ethnic maintenance in a following discussion.

\section{'Doing Danishness': Ethnic practices of LGE's in the USA and Argentina}

Berry's theory on acculturation processes largely relies on the wish or the absence of the wish to maintain ethnic practices and engage with your own ethnic group. Thus, one might say, acculturation according to Berry is largely about practices. This section explores LGE engagement in certain ethnic spaces, concretised by what Gans terms performing, preserving, commercial and promotional organisations as a measure of ethnicity's persistence.

\section{Doing Danishness at summer festivals and other annual activities}

Annual ethnic festivals fall into Gans' category of 'performing organisations'. Festivals of this sort were brought up in LGE interviews in both the USA and Argentina. For example, the annual summer festival in November in La Dulce in the Danish triangle (Danskertrekanten) in the Buenos Aires region goes back to 1897 and gathers Danish descendants from the whole region and beyond. The summer festival includes folk dance, theatre and Danish songs. A $4^{\text {th }}$ generation male interviewee from Buenos Aires, Malcom, 29, who participates in the summer festival expresses:

The annual Danish summer festival is something I get very much into and I do not want to miss it. I really have a strong bonding to it. I would love to keep it going. When I one day have children, I want them to be part of Danish traditions. I really identify, you know, that it's important because you feel roots. I feel I have something. I will love to keep it going. To teach it to my children eventually. I think it's a family thing. We all sort of identify in the same way, so we keep feeling the spirit. 
As Malcom expresses in this narrative, the summer festival creates a frame for sharing and reproducing Danish culture and identity. The festival thereby serves to preserve the Danish community in this area of Argentina and creates bonding social capital (Putnam, 2000) in the Danish Argentinian community. The quote highlights the importance of maintaining Danish traditions as a part of cultural practice and transmitting it to the next generation. Taking part in the traditions in the Danish community is one way of 'doing Danishness' with other descendants that is mentioned in all the interviews carried out in Argentina.

Like Malcom, Ellen, 64 and 4th generation immigrant from Denmark, highly engages herself in the annual activities of the Danish settlement of Tyler in Minnesota. Ellen for example helps out in organizing the annual town festival 'Æbleskiver Days' etc. 'ÆEbleskiver Days' is a three-day festival which takes places every year in July. It includes a grand parade, folk dancing, display of traditional crafts and the consummation of Danish foods such as 'smørrebrød' (Danish open-faced sandwiches), and æbleskiver (round Danish pancakes) of course. The festival also includes numerous fun games for children. She says:

A lot of Danish traditions have been carried on with our Æbleskiver Days in town, which also that started when I was in Highschool, I think. It was always just fun because a lot of people would come back to town. So it would be like a big family reunion of all your friends and relatives. Some of the people that I met when I was a kid, their families are still coming back.. so it's always fun to see those year after year [gets emotional].

Ellen expresses why Danebod and all the activities associated with it, is highly important as it provides her with a sense collective identity (Jenkins, 2008). The festival is like a big family reunion of all your friends and relatives; i.e. it 'unites' and provides bonding capital. The following quote confirms the sense of community through her use of "we":

I love this place. It's an important part of who I am (...) without this complex and what it brings to Tyler, Tyler would be like any other small town. We have got something special here.

Ellen's statement clearly also suggests that 'the complex', i.e. the Danish folk school and church, Danebod, makes her community unique. Jenkins (2008) has noted that the cultural content associated with ethnicity serves to differentiate 'us' from 'them' and mark the boundaries of the ethnic group. To Ellen, the traditions around Danebod are clearly key in categorising an 'us'.

Each year, Tyler also has a three-day children's camp at the folk school. The activities of the children's camp, including dancing, singing, playing games etc., are - like the festivals - a way to 'perform' ethnicity, though such practices may be seen as preserving in their nature as well because of the transmission to young generations. In fact, all the performing organisations attended by LGE's in both Argentina and the USA were inclusive of children. These included festivals, Christmas celebrations, the children's camp and also annual activities of the church, as we shall see.

At the Danish home of Chicago, a Danish old-people's home founded in 1891, Marie, 55, and a 4th generation Danish immigrant descendant, was even engaged in a commercial organisation (the home's beauty shop), when she was a child:

I used to come here when I was a little child [the Danish home], my grandmother and I would help down on the beauty shop [small shop that sells ethnic products etc. at the Danish home] (...) she actually started the women's auxiliary (...) and because of her work here in the home she was knighted (...) So I came here and since my Dad was here [retired and died here later on], I got more involved an now my mom and I come once a week. We do music, handbells (...) the residents participate (...) then I help out every year at the frikadeller-fest, the summerfest. So, yeah, the Danish home is becoming a bigger part of my volunteer activities these days.

The statement shows how Marie continued her engagement with the Danish Home since she was a child. It is obvious to think that opportunities for engagement in ethnic practices are more present in the Danish colonies on the prairie and the pampas than in large cities. Yet our data shows that this is not necessarily so. While in multiethnic Chicago another interviewee, Lily, hardly engaged in any ethnic practices, Marie, by contrast, was raised within an ethnic space of this city, allowing her to explore and later commit to ethnicity (Phinney \& Ong, 2007; Alba, 1990). 


\section{Doing Danishness through the church}

The church can be characterized as both a preforming and preserving organisation. In the USA and Argentina the church plays an important role in preserving ethnic practices in the local communities alongside religious practice. In the Argentinian case, the interviewees were very preoccupied with the role of the Danish church. Even though many were not practicing the religion as such, the Danish church and being a protestant linked them to their Danish background. One of the $3^{\text {rd }}$ generation male interviewees, James, 34, presented a narrative about the church and the Danish traditions;

The Danish meeting point was the church. My mother took us to the Danish church on special occasions like Easter and Christmas. Christmas is full of Danish traditions and to me the Danish is very connected to Christmas ... The youngsters do not want to go to church, but the church is an important meeting point. Here you can find Danish traditions such as 'Fastelavn' (a Danish kind of Halloween), Christmas and Danish food. Christmas is for me the most Danish, to go around the Christmas tree, eat Danish Christmas food and Santa Claus. When I was a child, we spent Christmas Eve together with two other Danish families.

James' quote also illustrates the children-friendly activities of the church to which his mother brought him along as a child. Moreover, it is interesting to note that the church seems much more appreciated due to its ethnic activities rather than its religious teachings; a feature present in many interviews in both the USA and Argentina. In James' case, as in many others, the practices around Christmas are particularly associated with his Danish background. The practices, such as going around the Christmas tree on Christmas Evening and singing Danish Christmas carols, are in particular associated with the Danish background. The role of the church during Christmas here serves as preserving and transmitting specific ethnic practises that otherwise could be transformed over generations to a larger extend.

A $4^{\text {th }}$ generation male interviewee, Malcom brings up the church and the Danish minister as a link to the Danish practises he engages in. In his case, the church is not mentioned as a meeting point where Danish traditions are practiced but links the church to the annual summer festival in La Dulce.

The church, the priest Steen Lehrfeldt, provides my connection to Denmark. My religion is protestant. It is not my usual business to go to church but this summer festival, the annual Danish summer festival is something I get very much into and I do not want to miss it. When I one day have children and I want them to be part of Danish traditions.

Even though Malcom does not spend much time in the church, he indicates that it matters to him. The local Danish minister, Steen Lehrfeldt, plays a significant role in the local Danish community and he and his wife always participate in the summer festival. In most late generation Danish Argentine cases, the church has played a more significant role in their childhood than it does in their adulthood. A $4^{\text {th }}$ generation female interviewee Cathrine, 26, expresses a stronger relation with the Danish church; 'I have always been a part of the Danish colony in Necochea, in the Danish church, school, and summer party'. In her case, practising Danish culture and traditions still plays an important role. In this rural community, the Danish church and the Danish minister has played a significant role in maintaining a strong bond to the Danish culture and practices.

Most respondents in the USA, including both third and fourth generation immigrants, did not express strong religious affiliations either. By contrast, as in Argentina, the Grundtvigian church attended by descendants in Tyler, Minnesota - had functioned as much as a cultural and social centre as a religious one. This was symbolically illustrated by the fact that both the folk school and the church were referred to as 'Danebod' - a united complex. The comprehension of the church as a most naturally linked to ethnic practices (i.e. folk dancing), just as it is in Argentina, is illustrated in the following quote. Anne, 31, a $4^{\text {th }}$ generation immigrant to Tyler, says:

Our church is very important to us - and to our grandparents and to our parents. We started folk dancing when we were really little.. kindergarteners? Maybe even littler.. erm and the adults danced as well in the gym hall [part of the folk school] and for the Æbleskiver Days, the town celebration that we have. (...) we continue to do it at children's camp at the folk school.. and my grandmother used to teach it and then my parents used to teach it and now Julie [the sister] and I teach it for the children that come to camp.

However, as the church was stated as 'very important' to Anne, religion is apparently not. When asked about her relation to religion, she says: 'Oh, I'm not very religious, I should be more religious than what I am (...). 
But we go to church, I supposed because we were told we were supposed to when we were kids. [laughs]'. To Anne and others from Tyler, more so the history and the tradition of the church was seen as important.

The Danish churches in both the USA and Argentina could be considered both preserving and performing ethnic organisations, which engage many people of Danish descent, including later generations. This mainly seems due to the ethnic and social aspects and children-friendly activities which are offered through the church. Hence, like other ethnic spaces, the church offers participation in practices which help children explore their ethnic backgrounds and thus assists intergenerational transmission of ethnicity. It also offers the frames for sharing and (re)constructing ethnic identity (Nagel, 1994; Wu \& Ida, 2018). Like the church is primarily enjoyed due to its 'social side', so is it a place for socialisation. Maria, a $4^{\text {th }}$ generation female interviewee from a rural area in Argentina, cements this as she says: 'Now there is a new chapter in the Danish Argentine history because now we'll have a new minister who is not Danish. So now we will be making our minister more Danish instead of him making us more Danish...'. Maria thus very directly suggests that this church, so far at least, has been a place where you are 'made Danish'.

In both the USA and Argentina, whether the church functioned as a space for ethnic socialisation seemed dependant on different things. In the USA, for example, it seemed much dependant on whether the church considered itself Danish or not and took pride in ethnic preservations. To the Grundtvigian church in Tyler, for example, this had been a decided goal ever since its establishment. In Argentina, the personal motivation and background of the minister also appeared to be significant, as exemplified in the statement above. Finally, the church as perceived as decidedly 'Danish' is influenced by its location and ability to attract an ethnic congregation.

\section{Doing Danishness by travelling to Denmark}

Another practice that has been present among interviewees in both Argentina and the USA and to various extents across the generations is to visit Denmark. Cathrine, a $4^{\text {th }}$ generation LGE from Argentina, for example says:

When I was 18, I travelled to Denmark where I was for four months. Since then I have been at folk school in Ollerup (small Danish town). Here I met people from all over the world, also Denmark. I would like to travel back to Denmark when I have finished my education as a building engineer. I loved being in Denmark. I felt I was home.

In this narrative, the LGE woman expresses a sense of belonging to Denmark as a 'home'. This feeling is connected to identification with Danish society and culture. Some of the other interviewees have expressed similar feelings; some even choose to stay in Denmark, where others return to Argentina because that is where they feel that they belong.

Travelling to Denmark and gaining knowledge and experiences in 'the old country' may in many cases provide a 'reassurance' of Danish ethnic identity. By contrast, in one case in the USA, an LGE's expectations and perceptions of Denmark 'clash' with experienced versions of ethnicity upon arrival. Anne from Tyler says:

It was somewhat disappointing. Like to us, or at least to me. I don't know what I was expecting but it was not what I was expecting. We saw a group of native American people in the Strøget [pedestrians shopping street in Copenhagen] singing which is weird because we live so close to South Dakota and Pipestone where there is native American culture (...) and then we went to Denmark and there was native Americans. We wanted to see folk dancers and instead we saw native Americans [laughs]. We thought 'this is strange'. It's just not what we thought.

To Anne the trip has produced disappointment and perhaps somewhat unease due to a consequent destabilised identification. Instead of reassuring the respondent of her perceived Danish ethnic identity, this forces upon her a 'rethinking' of it. Similar responses to newer versions of ethnicity have been found in other studies too (Levitt, 2009; MacIntosh, 1993). By far the most of our LGE respondents, however, present positive descriptions of their travels to Denmark. Like this was the case with Cathrine from Argentina, so are Ellen's memories from Denmark so fond that she becomes emotional in speaking of them.

Peter, 40, is a 4th generation immigrant whose family settled in the town of Blair, Nebraska. In Blair, John went to Dana College, a Danish college that originally was founded as a Danish inner mission seminary. During his college studies, Peter immersed himself in Scandinavian history. The culmination of his studies became a 6 months stay in Denmark, where he worked for a museum: 
It was probably the most fun time of my life, living in Denmark. I loved working for the museum, because my job was really to travel around the island of Fyn and document some of the agricultural architecture that was there (...) We [a partner from work and himself] drove around the island a lot, told lots of stories and... I really learned a lot about Denmark there and it was a great chance to learn some Danish, though it's at rest here now, I haven't used it much the past ten years (...) I love the language and the culture.

Illustrated by the LGE statements, not least Peter's travels to Denmark, to the 'homeland', seem to serve different functions to both the American and Argentinian LGE's. For one, ethnic practices such as touring the country, visiting cultural highpoints or planning a stay at a folk school, for example, seems to be practices which are partly associated with the fun, adventurous, open-minded exploration of life and (ethnic) identity during youth, which is perhaps also considered somewhat exotic and prestigious. On the other hand, travels to Denmark also sometimes involve exploring historical places, such as visiting the old family farm. As noted by Kayser Nielsen (2005), reconnection with roots and history, for example, provides a reassurance of identity in a globalised world. Taking an interest in historical places, hence, becomes a way to find one's way home. Often, travels also include immersing into Danish culture and taking up the opportunity of practicing the language. Thereby, the travels would comprise both performing and preserving elements.

\section{Doing Danishness by speaking Danish}

The ability to speak Danish or not seems one of the most remarkable differences among LGE's in the USA and Argentina. Organisations which promote ethnic literacy falls into Gans' category of a preserving organisation, though language practice also takes place at home, as what Gans would term an ethnic 'micro-social home activity'. A few LGE interviewees in the USA had taken Danish classes, but none were really comfortable in speaking the language and many knew, except for Peter, nothing more than a few phrases. John, a $4^{\text {th }}$ generation interviewee who grew up in one of Tyler's neighbouring towns, says:

My folks spoke it [Danish], I think until they went to school. But that's one of the things that is different now. I think that when the Danes came over, they said we got to learn English. And unfortunately they haven't kept it up, a lot of them up here in Tyler have, I think - to some extent (...) they would have Danish words or phrases.

John's statement is confirmed by interviews with earlier generations, showing that ability to make oneself understandable or complete most of a Danish lullaby or carol, for example, in Danish was only held by earlier generations such as around the second, though as the statement also illustrates, this also depended on place. Therefore, it seemed that the successful transmission of Danish language between generations had stopped some time ago. This contrasted LGE's in Argentina, well-illustrated by the fact that while most interviews were completed in Danish in Argentina, this only accounted for one second generation interview - through most of it at least, in the USA. The importance of being able to speak Danish is articulated by one of the male interviewees, Daniel, 55 who is $3^{\text {rd }}$ generation Danish Argentine:

In Argentina, we keep speaking Danish, whereas in North America they do not speak Danish, they speak English. But here in Argentina we speak Danish. It is important to be able to speak with the family in Denmark. Here in Argentina, in everyday life, it doesn't matter.

Speaking Danish is here referred to in connection to the relation with the family in Denmark. The relational character expressed by this interviewee indicates the importance of being able to communicate with the family in Denmark. The point made that speaking Danish doesn't matter in Argentina is linked to the fact that Spanish is the native language and that Danish is not spoken very often in Argentina. Another male LGE from Argentina, Malcom, also address the Danish language in his life story. He is one of the two interviewees who does not speak Danish and has never been to Denmark:

There was a time when I was very preoccupied with the Danish, so I talked to my grandmother about it. It is interesting to know where you come from. When I was very small, I spoke only Danish. My first word was traktor (tractor)! My father did not understand Danish so my mother stopped speaking Danish to me. 
It is interesting to reflect upon why Danish language seems to have survived to a much greater extent in Argentina than in the USA. The statement above suggests that transmission of Danish language from generation to generation in most cases depends on both parents' ethnic background. A possible conclusion could therefore be that LGE language maintenance in Argentina result from later interethnic marriages. Another possibility is that the Danish ethnic minority group in Argentina was more so perceived as different, by the in-group as well as the out-group (Goffman, 1963), both in terms of visual appearance and religion, and that this may have caused increased 'ethnic closure' during the first generations. Over time, Spanish have become the spoken language in the Danish Argentinian families. Most of the young informants have therefore learned to speak Danish during their stay in Denmark and maintain this skill by speaking Danish with older generation family members in Argentina as well as with family back in Denmark. There seems to be a link between the LGEs travel to Denmark and their Danish language comprehension.

The ethnic practices which LGE's in both Argentina and the USA engages in seem mostly of what Gans' terms 'performing' or 'preserving' natures. 'Doing' Danishness is thus often expressed as related to ethnic festivals or other annual activities such as Christmas and 'Fastelavn', many of which are also associated with the church. Those activities provide frames for sharing and reproducing Danish culture and identity. Moreover, they provide bonding social capital within the ethnic group and mark the boundaries of an 'us' (Putnam, 2000). 'Doing' Danishness also involves travels to Denmark and engagement with Danish language. Travels to Denmark sometimes work as an assurance of ethnic identification and provides a chance to engage further with the language and the culture. The interviews with LGE's in the USA and Argentina also show remarkable differences between the two groups in terms of ethnic practices, most noteworthy, perhaps in relation to ability to speak Danish and persistent contact to Denmark throughout generations.

\section{'Being Danish': Ethnic identity of LGEs in the USA and Argentina}

Conceptualising being Danish is closely related to identity and belonging, which involves the interplay of individuality, community and solidarity. This approach enables an understanding of the interplay between subjective experiences of the world and the cultural and historical setting in which they are formed (Gilroy 2006). Identity is thus related to both the individual "me" and the collective "we" that sets the scene of distinguishing between inclusion and exclusion of the group.

Researchers have noted that the LGE's are typically products of several generations of intermarriages and complex family backgrounds (Alba, 1990; Gans, 2014, 2015). This also means that they have multiple options to choose from in terms of ethnic identification (Waters 2014). The issue of having a mixed ethnic background is addressed by most of the informants in their narratives. Malcom expresses the identification with being a mix of ethnicities, but mainly identifies with being Danish as well as Argentine:

I feel really identifying with being a mixture. Like all Argentines, we are European descendants. We are all Europeans born in Argentina. We are a mixture of all European countries. It's beautiful getting to know that I have Danish, Irish, Italian and Spanish blood in my veins, but it is only the Danish I identify with. I fully identify with the Argentine flag and the Danish flag.

This quote illustrates how having a mixed ethnic background may influence identity and sense of belonging. The identification of being both Argentine and Danish support the idea that it is possible to feel belonging to more than one place. Having a mixed ethnic background, in this case Danish, Irish, Italian and Spanish does, however, not necessarily mean identification with all of them. Despite multiple ethnic options, identification with only the Danish background, is expressed by several of the interviewed LGEs in Argentina and some in the USA. Jill, a $4^{\text {th }}$ generation interviewee from the USA, for example, considers herself Danish, even though she also has an English and Irish background: 'I feel like I'm all Danish even though I'm half English and Irish. But my Grandpa used to say that the Irish really were Danes. So who knows? Anyway, I consider myself Danish'. The identification with being Danish that this LGE woman expresses indicates how transmission of ethnic identity is passed on from one generation to another. In both the American and the Argentinian case the matter of being Danish is essential to their identities. Malcom from Argentina also expresses how the Danish ancestry plays an essential role to his identity:

Because of my look and everything, all my friends call me the Viking, the Dane, because of the beard. All my friends know that I am a Danish descendant because I always told them. I am proud of it, so it is like I'm promoting it. It is a good story to tell!

Identification with being Danish is here referred to as being very positive and something to be proud of. This gives an example of that ethnicity is also linked to social positioning (Jenkins) where it can be used as a part 
of the individuals narrative and in this case be 'a good story to tell'. The personal narrative is a part of identity construction that includes ethnicity, which can be differently perceived in various contexts and over time. There is also a link to cultural capital (Bourdieu, 1986) that in this case is perceived as rather high. As mentioned earlier, migration scholars on both sides of the Atlantic have recently turned their attention towards studies on the historical placement of European migrants within American ethno-racial hierarchies. The studies suggest that Scandinavians have historically placed themselves favourably by aspiring to be part of an Anglo-Saxon heritage. Moreover, in her recently published book The Scandinavians in Chicago (2019), Erika Jackson shows how Scandinavians from their arrival in the late 1800's were seen as the embodiment of what was considered white superiority and thus enjoyed racial privilege. Whether Scandinavians in Argentina similarly placed themselves favourably within ethno-racial hierarchies here have not been researched to the same extent as in the USA, though LGE expressions of pride in Argentina suggest that later generations in both places feel prideful to proclaim their ethnic background, drawing, perhaps, on the privileges and passages that were enjoyed by their ancestors and which may still, to certain extent, prevail today.

In most of the life stories narrated by the informants in both Argentina and the USA the identification with being Danish is expressed in various degrees. Benjamin, 38, a $4^{\text {th }}$ generation from the USA articulates his identification with being Danish through familiarity with Denmark and the Danish language:

We just recently watched this Danish TV series, "the Killing" (...) Hearing the Danish, I could almost understand everything that was being said. I think, having heard that while growing up, something about that has sunk into my subconscience in some way. It feels familiar to me, it feels that it is not far removed from who I am. I don't speak Danish, though my brother does (...) I feel a certain familiarity with Denmark, much more so than I would with, say, Germany, though I have a German background as well. But I don't have identification with that, I still have identification with Denmark. So, why did that win out over other aspects of my ancestry, I don't know. But it's still there. I don't know if it will continue with my own son. Who knows? It might not at all. But I feel a certain connection.

In this narrative the impact of socialisation as an important part of identity construction is articulated with reference to how culture is practised within the family and a part of constituting habitus (Bourdieu, 1986). In this case familiarity with the Danish language is mentioned as giving connection to Denmark that is stronger than the informant's ties to his German background. This is yet another example of how some of the LGEs interviewed feel stronger connection to their Danish background than their other ethnic backgrounds because of the transmission of Danish culture in the local community and within families. With reference to the first part of the analysis on ethnic practices, it seems clear, thus, that socialisation and possibilities for practising and exploring ethnicity during childhood and youth is essential to the successful transmission and later internalisation of ethnic identity. It seems likely, therefore, that this has been one of the reasons that Benjamin's Danish background 'won out' over the others. Whether the status associated with an ethnic background may also contribute to a more likely internalisation of this particular ethnic identity, is another worthwhile research study.

Some informants express another understanding of their ethnic identities and belongings, which more so can be understood as expressions of hybrid identities. A female LGE from Argentina, Emilie, 43, talks of her Danish background as an important part of her social life and identity:

My mother was not pleased with me having friends that didn't have a Danish background. Today I still have many friends with Danish background. There was a time in life where it was hard to figure out whether you are Danish or Argentinian. I have accepted that I'm a hybrid, a mixture.

In this quote the LGE woman expresses how having a mixed ethnic identity is experienced and accepted as being a hybrid. The fact that her Danish background still plays a role as constituting her identity and social network might have been influenced by the fact that her mother did not like for her to have friends that 'didn't have a Danish background', hence she favoured to stay amongst other Danes. Having a mixed background does not necessarily mean that the Danish is considered the more significant one. This is also expressed by Christine: 'I think of myself as Argentine, but I have many things from Denmark. I do not feel that I'm Danish. Here in Argentina we have a mix of culture'. Even though this woman expresses that she has 'many things from Denmark', she does not feel Danish. Her sense of belonging and identity is bound to being Argentine, which is based on having 'a mix of culture'. This understanding is also narrated by Lily, a $4^{\text {th }}$ generation interviewee from Chicago, who addresses how her sense of self has been impacted and shaped from transmission of multiple ethnic backgrounds: 
I don't feel that being Danish necessarily defines me (...) I mean, there's definitely little bits of the Danish culture that pop up in my life and that I find nice, but ultimately there's so much more that I think has been assimilated through interacting with people who aren't Danish (...) All these traditions kind of fostered in. My mom's side of the family would always try and make things a little more Irish (...) Nothing ever really stuck with that, Danish is the only stuff that ever really stuck. (...) I'm at where I am because somebody 4 generations ago decided to come over here and work 60 hour weeks.

What defines a person's belonging/identity is by this LGE expressed as a mix of traditions from the ethnic backgrounds and not a specific one. Thus, in cases where multiple traditions have been transmitted, the belonging to one specific background becomes weaker - as 'bits which pop up now and then'. This is what Gans refers to as 'symbolic ethnicity'.

In the LGE narratives in this study there does not seem to be a strict division between generations, particularly between the $3^{\text {rd }}$ and $4^{\text {th }}$ generations in regards to 'being Danish'. This indicates that there is not necessarily a linear progression of acculturation. Rather, the variations that are presented in the LGE life stories indicate that context is crucial, since individual identity as well as group identity is constructed in a certain time and contextual frame. Since being a part of an ethnic community allows for the exploration, practise and transmission of ethnicity, it seems to have a strong impact on the construction of individual identity, of who you are. Ellen says:

I love this place. It's an important part of who I am and I think it's important.. the people of the community, I don't think realise probably how important this place is to the community (..) I don't think they understand that without this complex and what it brings to Tyler, Tyler would be like any other small town. We have got something special here. The fact that it is on the national list of historical places tells me something. It's unique, it's interesting, a fun place to be involved with.

The role that the community play in preserving the ethnic identities and practices is here linked to the specific place. In this case Tyler is perceived as a special place because of the Danish community where the identification with the Danish background remains strong. This indicates the importance of location as a matter of context to which belonging can be more or less strong. In the Danish colony of Tyler, and among many in the Danish colonies in Argentina too, ethnicity has manifested in practices and self-perception throughout a number of generations. In larger cities, such as Buenos Aires and Chicago, certain ethnic spaces may similarly offer possibilities for exploring and ultimately internalising ethnicity as an important part of identity. However, it also seems likely that there may be a greater potential for different traditions to 'foster in' within the urban context, through engagement and intermarriage with other ethnicities over generations, which may result in hybrid identities and symbolic ethnicities - faster.

Though all of the LGE interviewees express engagement with ethnic practices, the degree of involvement seems to vary, just as expressions of 'being' Danish and identification with this particular ethnic background varies too. Whilst some LGE's express a clear sense that they identify with being Danish despite a mixed ethnic background, others honour their mixed ethnic background, well aware that multiple traditions and belongings have 'fostered in' throughout the generations. With reference to Max Weber (1978), Jenkins notes that 'people come to see themselves as belonging together - coming from a common background - as a result of acting together' (2009, p. 10), not the other way around. This indicates that 'acting' together or engaging in ethnic practices plays a key role to later ethnic identification. This theory goes hand in hand with other research on ethnicity which claims that 'exploration' of ethnicity during childhood and youth, in particular, is key to later decisions of commitment and internalisation of that ethnic identity as part of a matured 'adult' identity (Phinney \& Ong, 2007; Woofter, 2019). Following those ideas, it seems that the LGE's in both Argentina and the USA, at least to some extent, have been offered the frames for engaging in and exploring what it means to 'be Danish' through their childhood and youth. Variations in identification, however, may pertain to varying possibilities and motivation for engagement.

Expressions of pride in the Danish ancestry, moreover, as one of the interviewees from Argentina stated that this was a 'good story to tell', suggest that ethnicity is linked to social positioning. This study thus supports existing research on Danish emigration to the USA, which claims that Danish migrants have historically placed themselves favourably within American ethno-racial hierarchies. Though this is an unexplored field of research in relation to Danish/Scandinavian emigration to Argentina, it seems likely that this is also the case here. 


\section{Discussion}

The LGE life stories in Argentina and the USA show certain differences between the two groups. Particularly the Argentinians' greater ability to speak Danish was remarkable. This highly contrasted the US LGE's who were, at most, able to say a few sentences in Danish, suggesting that the successful transmission of Danish language in the USA had stopped a while ago. The LGE's in Argentina also expressed less concern that ethnic practices and self-perceptions were dwindling than LGE's in the USA. Yet one Argentinian LGE predicted that Danish-Argentinians would 'at some point' reach the same stage as those in the USA, where perceptions of 'Danishness' had now developed into being far removed from current perceptions of 'Danishness' in Denmark. From her perspective, thus, the Danish-Argentinians had not yet reached this stage. Finally, many of the Argentinian LGE's expressed a clear sense of belonging to Denmark. To those, travels to Denmark often provided an assurance of ethnic identification and some had even chosen to settle in Denmark more permanently. By contrast, the LGE's in the USA had rather been to Denmark for shorter periods on visits. One US interviewee expressed disappointment with her visit, since she had expected so see and experience something else. This may resemble a lack of continuous contact with Denmark throughout the years. A continuous contact with Denmark seems to have been stronger in Argentina, particularly since the engagement of Danish ministers had continued in Argentina until very recently. As stated by an Argentinian LGE, the Danish ministers had thus been able to make the Danish-Argentinians 'more Danish' throughout the generations and develop understandings of ethnicity in line with ethnicity's development in Denmark.

Like variation in ethnic practices, there does also seem to be variation in the extent to which 'being Danish' constitutes a defining part of LGE identities. Whilst all interviewees within both groups have more or less mixed ethnic backgrounds, some identify primarily with their Danish background, while others honour the fact that multiple backgrounds have 'fostered in', leading to a higher degree of hybrid identities, symbolic ethnicities and assimilation. It seems that where transmission of 'Danishness' has been strong throughout generations, it has 'sunk into subconscience', as one LGE states, and carried substantial influence to identification and habitus.

As the two cases thus differentiate in terms of place, many other aspects, not at least the period of time in which initial migration took place are aligned. Yet as concluded above, our cases do not show the precise same results when it comes to forms of acculturation. There are indications that assimilation is more pronounced in the USA. One explanation for this may also while they all migrated to 'the Americas', Danes were more visibly different in the south than in the north. This could have possibly led to increased ethnic closure in the south. Another explanation may pertain to the simple matter of immigrants' initial choice of settlement. Jeppesen (2010), for example argues that in the USA, Danes and Swedes have been assimilated faster than the Norwegian immigrants, for example, simply due to the fact that Danes settled in less isolated areas, so that their descendants had easier access to urban areas, better job opportunities and contact to other ethnic groups.

This study also shows that since ethnic identification and ethnic practices may sometimes be more present in the $4^{\text {th }}$ than, say, the $3^{\text {rd }}$ generation, acculturation does also not necessarily progress linearly. Rather, the study supports Jeppesen's findings, showing that the contextual frames of the interviewees, throughout the generations, have had significant impact on the current stage of ethnicity. It is interesting to note that all the "performing organisations' that had engaged the LGE's were children-friendly activities. They were offered, not least, through the church. Indeed the frames for exploring and practising ethnicity during childhood and youth seems crucial to later identification and internalisation of ethnic identity as a significant part of a matured identity. This puts certain locations and ethnic spaces at centre stage as a type of context. In the Danish colonies in the USA and Argentina, socialisation within an ethnic community has supported ethnic transmission and manifestation in practices and self-perceptions throughout the generations. Where ethnic transmission has been strong through the generations, it has 'sunk into the subconscious' and carried substantial influence to identification and habitus. Though it is also possible to be raised within a mono-ethnic space of the city, there seems a greater potential for different traditions to 'foster in' through the generations in rural areas. Placement within an urban setting such as Buenos Aires or Chicago may thus, as our interviews also show, lead to more hybrid identities, fewer Danish practices, more loosely tied belongings and symbolic ethnicities - faster. By conclusion this study therefore indicates that context, throughout the generations, rather than generational stage per se, plays a central role in defining the contours of the acculturation process. Thus, it may also be essential to when ethnicity 'enters into darkness'.

Hence, while this study points towards that the gaze could be directed towards a focus on context and ethnic space in policy discussions on integration and acculturation, it is important to note that both country cases indicated that Danish practices and identities did not influence interviewees' national belonging to the respective country negatively. At least when we are talking $3^{\text {rd }}$ and $4^{\text {th }}$ generations. In both the USA and Argentina, the LGEs to varying degree expressed the importance of maintaining their Danish ethnicity (as a part of their identity and belonging) even though this changes over time and generations. There were no indications, however, that they were less integrated into Argentinian or American society on that account - on the contrary. 


\section{Biographical note.}

Pernille Skovgaard Christensen was employed as a $\mathrm{PhD}$ fellow at the Centre for Migration and Diversity, Aalborg University in 2014. Pernille's PhD project is part of a joint research project which examines historical and contemporary migration flows to - and from Denmark. In close collaboration with the Danish Emigration Archives in Aalborg, Pernille's project focuses on Danish emigration to the USA and to Australia and dwells on dynamics of ethnic maintenance across generations. Pernille has published more journal articles on Danish emigration.

Trine Lund Thomsen is associate professor at the Department of Culture and Learning, Aalborg University, Denmark. Trine has published widely on issues related to migration to Denmark and migrants' integration in the Danish labour market. Furthermore, she has co-authored a range of publications on narrative research. Engaged in the same research project as Pernille, Trine has recently researched a case of Danish emigration, exploring the life practices and self-perceptions of people of Danish descent in Argentina.

\section{References}

Alba, R. D. (1990). Ethnic identity: The transformation of White America. New Haven: Yale University Press. Bækhøj, L. (1948). Danske i Argentina. Copenhagen: Det Danske Forlag.

Berry, J. W. (1989). Psychology of acculturation. In J. J. Berman (Ed.), Nebraska symposium on motivation, 1989: Cross-cultural perspectives current theory and research in motivation, 37 (pp. 201-234). Lincoln, NE, US: University of Nebraska Press.

Berry, J. W. (1997). Immigration, adaptation and acculturation. Applied Psychology, 46(1), 5-34. doi:10.1111/j.1464-0597.2006.00256.x

Berry, J. W., Phinney, J. S., Sam, D. L., \& Vedder, P. (2006). Immigrant youth in cultural transition: acculturation, identity and adaptation across national contexts. New Jersey: Lawrence Erlbaum Associates, Inc. Publishers.

Bertaux, D., \& Thompson, P. (2009). Introduction. In D. Berteaux \& P. Thompson (Eds.), Between generations family models, myths and memory (pp.1-12). New Brunswick, NJ: Transaction Publishers.

Bjerg, M. M. (1996). Generations of Danishness in the Argentine Pampas. In I. Svanberg (Ed.), Ethnicity, minorities and cultural encounters. Uppsala: Centre for Multiethnic Research.

Blanck, D. (2014). A mixture of people with different roots: Swedish immigrants in the American ethno-racial hierarchies. Journal of American Ethnic History, 33(3), 37-55. doi:10.5406/jamerethnhist.33.3.0037

Bo, I. G., Christensen, A., \& Thomsen, T. L. (2016). Narrativ forskning: Tilgange og metoder. In I. G. Bo, A. Christensen \& T.L. Thomsen (Eds.), Narrativ forskning: Tilgange og metoder (pp. 13-33). Latvia: Hans Reitzels Forlag.

Bourdieu, P. (1986): The forms of capital. (R. Nice. Trans.) In J. G. Richardson (Ed.), Handbook of theory and research for the sociology of education (pp. 41-258). New York: Greenwood Press.

Brøndal, J. (2014). "The fairest among the so-called White races": Portrayals of Scandinavian Americans in the Filiopiestistic and nativist literature of the late nineteenth and early twentieth centuries. Journal of American ethnic history, 33(3), 5-37.

Douma, M. J. (2014). How Dutch Americans stayed Dutch: An historical perspective on ethnic identities. Amsterdam: Amsterdam University Press

Gans, H. J. (2014). The coming darkness of late-generation European American ethnicity.' Ethnic and Racial Studies, 37(5), 1-9. doi:10.1080/01419870.2013.827796

Gans, H. J. (2015). The end of late-generation European ethnicity in America? Ethnic and Racial Studies, 38(3), 418-429. doi:10.1080/01419870.2015.967707

Glaser, B. G., \& Strauss, A. L. (2012). The discovery of grounded theory - Strategies for qualitative research. New Brunswick, USA: Transaction Publishers

Goffman, E. (1963). Stigma; Notes on the management of spoiled identity. Englewood Cliffs, NJ: Prentice Hall.

Hvidt, K. (1976). Danske Veje Vestpå - en bog om udvandringen til Amerika. Copenhagen: Politikens Forlag.

Jackson, E. (2019). The Scandinavians in Chicago: The origins of White privilege in modern America. University of Illinois Press.

Jacobson, M. F. (2006). Roots too: White ethnic revival in post-civil rights America. UK: Harvard University Press.

James, W. Y. (2019). Imprint of Racism: White Adult Males' Transformational Experience from Racial Antipathy to Racial Reconciliation. American Journal of Qualitative Research, 3(1), 93-116. https://doi.org/10.29333/ajqr/5813

Jenkins, R. (2008). Rethinking ethnicity: Arguments and explorations. London: SAGE Publications Ltd

Jenkins, R. (2011). Being Danish: Paradoxes of identity in everyday life. Copenhagen: Museum Tusculanum Press.

Jeppesen, T. G. (2010). Skandinaviske efterkommere i USA: Etniske grupper eller kerne-amerikanere? Odense: Odense Bys Museer. 
Jiménez, T. R. (2010). Affiliative ethnic identity: A more elastic link between ethnic ancestry and culture. Ethnic and Racial Studies, 33(10), 1756-1775. doi:10.1080/01419871003678551

Kenna, J., \& Russell III, W. (2018). The Culture and History of Standards-Based Educational Reform and Social Studies in America. Journal of Culture and Values in Education, 1(1), 26-49. Retrieved from http://cultureandvalues.org/index.php/JCV/article/view/2 (DELETE THIS REFERENCE)

Kjær, G. (1991). Landet bag hav. Om Argentina og om danskere og deres efterkommere i Argentina. Odense: Odense Universitetsforlag.

Krishnan, A. \& Berry, J.W. (1992). Acculturative stress and acculturation attitudes among Indian immigrants to the United States. Psychology and Developing Societies, 4(2), 187-212. doi: $10.1177 / 097133369200400206$

Levitt, P. (2009). Roots and routes: Understanding the lives of the second generation transnationally. Journal of Ethnic and Migration Studies, 35(7), 1125-1242. doi:10.1080/13691830903006309

Levitt, P., \& Schiller, N. G. (2004). Conceptualising simultaneity: A transnational social field perspective on society. The International Migration Review, 38(3), 1002-1039. doi:10.1111/1747-7379.2004.tb00227.x

Lundström, C. (2014). White migrations: Gender, whiteness and privilege in transnational migration. Palgrave Macmillan

MacIntosh, J. (1993). Danskere i midtvesten: Elk Horn-Kimballton bosattelsen 1870-1925. Akademisk Forlag

Miller, R. L. (2000). Researching life stories and family histories. Trowbridge, GB: Sage Publications Ltd.

Nagel, J. (1994). Constructing ethnicity: Creating and recreating ethnic identity and culture. Social Problems, 41(1), 152-176. doi:10.2307/3096847

Nielsen, N. K. (2005). Steder i Europa: Omstridte byer, granser og regioner. Aarhus: Aarhus University Press.

Øverland, O. (2000). Immigrant minds, American identities: Making the United States home, 1870-1930. Urbana \& Chicago: University of Illinois Press.

Pease, B. (2010). Undoing privilege: Unearned advantage in a divided world. London and New York: Zed Books Ltd.

Phinney, J. S. (2003). Ethnic identity and acculturation. In K. M. Chun, P. B. Organista, \& G. Marín (Eds.), Acculturation: Advances in theory, measurement and applied research, 63-81. Washington: American Psychological Association.

Phinney, J. S., \& Ong, A. D. (2007). Conceptualisation and measurement of ethnic identity: Current status and future directions. Journal of Counseling Psychology, 54(3), 271-281. doi:10.1037/0022-0167.54.3.271

Putnam, R. D. (2000). Bowling alone. The collapse and revival of American community. US: Simon \& Schuster.

Redfield, R., Linton, R., \& Herskovits, M. J. (1936). Memorandum on the study of acculturation. American Anthropologist, 38(1), 149-152.

Ricoeur, P. (1984). Time and narrative I-III. Chicago: University of Chicago Press

Rosenthal, G. (1993). Reconstruction of life stories: Principles of selection in generating stories for narrative biographical interviews. The Narrative Study of Lives, 1(1) 59-91.

Waters, M. C. (1990). Ethnic options: Choosing identities in America. Berkeley, CA: University of California Press

Waters, M. C. (2014): Ethnic identities in the future: The possible effects of mass immigration and genetic testing. Ethnic and Racial Studies, 37(5), 766-769. doi:10.1080/01419870.2013.871054

Weber, M. (1978). Economy and society (G. Roth and C. Wittich, Eds.). Berkely: University of California Press.

Woofter, S. (2019). [Book Review]: Building Equity: Policies and Practices to Empower All Learners. American Journal of Qualitative Research, 3(1), 136-139. https://doi.org/10.29333/ajqr/5815

Wu, B. \& Ida, K., A. (2018). Ethnic Diversity, Religion, and Opinions toward Legalizing

Abortion: The Case of Asian Americans. Journal of Ethnic and Cultural Studies, 5(1), 94-109. 